\title{
Use of stochastically generated weather records with range- land simulation models
}

\author{
J.R. WIGHT AND C.L. HANSON
}

\begin{abstract}
We compared long-term historical and stochastically generated weather records in terms of their statistical attributes and effects on herbage yield and runoff forecasts calculated from model simulations. The historical and synthetic air temperature and solar radiation records were in good agreement in terms of monthly means and extremes. The synthetic precipitation record failed to simulate extreme precipitation events which significantly reduced forecasted runoff values. Yield forecasts were similar using either historical or synthetic weather records.
\end{abstract}

Key Words: forage yield model, rangeland simulation model, stochastic weather generation, yield forecast, hydrology model

Rangeland simulation models such as SPUR (Simulation of Production and Utilization of Rangelands) (Wight and Skiles 1987) and ERHYM (Ekalaka Rangeland Hydrology and Yield Model (Wight and Neff 1983, Wight 1987) have been developed as tools for both research and management. As management tools, they can be used to predict hydrologic, plant, animal, and/or economic responses to environmental changes and management inputs. Long-term simulations provide a means for making management decisions by evaluating and comparing management options in terms of their impact on livestock production and site stability. Through stochastic processes, model outputs can be bracketed within levels of probability of occurrence (Wight et al. 1984).

A major limitation to the application of natural resource simulation models is the lack of long-term weather records, especially for remote areas. To overcome this limitation, stochastic procedures like those described by Larsen and Pense (1981), Nicks and Harp (1980), Richard (1981), and Richardson and Wright (1984)

\footnotetext{
Authors are range scientist and agricultural engineer, USDA-ARS, Northwest Watershed Research Center, 800 Park Boulevard, Plaza IV, Suite 105, Boise, Idaho 83712 .

Contribution from the USDA-ARS, Research Center, Boise, Idaho 83712

The authors acknowledge R.J. Lorenz, former director of the USDA, ARS Northern Great Plains Research Laboratory, Mandan, N.Dak., for his help in obtaining the long-term weather records from Mandan, N.Dak.

Manuscript accepted 11 August 1990.
}

have been used to generate daily weather records that are statistically comparable to historical records for the same location. Model simulations using synthetic weather records have been used successfully to develop crop yield forecasts (Arkin et al. 1980, Richardson 1985).

The purpose of this paper is to compare a long-term historical weather record with 2 synthetic weather records in terms of their statistical attributes and their effect on herbage yield and runoff forecasts calculated from rangeland model simulations.

\section{Material and Methods}

The historical weather record used in this study is from Mandan, N.Dak. It includes 71 years (1914-1984) of daily precipitation and maximum and minimum air temperatures. Solar radiation data were available for only 1954 through 1984 . Thus it was necessary to use synthetic solar radiation data with the historical precipitation and temperature weather record. Previous work has shown that outputs from the rangeland model used in this study are little affected by use of synthetic solar radiation values (Wight and Neff 1983, Wight 1987). The 31 years of historical solar radiation data were used to calculate the parameters used to generate the 71-year record.

The historical record is representative of the Northern Great Plains. The climate is semiarid with long cold winters, hot summers, and an erratic precipitation pattern. The native vegetation is classified as mixed prairie (Weaver and Clements 1938) with blue grama (Bouteloua gracilis), western wheatgrass (Agropyron smithii), thread leaf sedge (Carex filifolia), and needle and thread (Stipa comata) as the dominate species (Rogler 1951).

\section{Synthetic Weather Record}

Synthetic weather records were generated with the climate generator model CLIMGN described by Richardson et al. (1987). CLIMGN is based on procedures developed by Richardson (1981) and a computer program described by Richardson and Wright (1984). A first-order Markov chain is used to generate the occur- 
rence of wet or dry days. For wet days, the two-parameter gamma distribution is used to generate precipitation amounts. Air temperatures and solar radiation generation are based on the weakly stationary generating process described by Matalas (1967) and are conditioned by the occurrence of wet and dry days. In this study, CLIMGN was modified to use monthly means with standard deviations rather than coefficients of variation for generating daily maximum and minimum temperatures because during winter months, some of the means become very close to zero which result in unrealistic coefficient of variation values.

We generated two 71-year synthetic records for comparison with the historical record (HISWR). One synthetic record (TSGEN) was composed of historical precipitation data and generated maximum and minimum air temperatures and solar radiation. In the other synthetic record (ALLGEN), precipitation, air temperatures and solar radiation were generated. In TSGEN, the generation of air temperatures and solar radiation were conditioned on the occurrence of wet and dry days in HISWR. Precipitation and average temperature means for the historical and synthetic records were compared using a $t$-test.

Parameters for the CLIMGN model were calculated from the last 20 years of HISWR using the GENPAR program as described by Skiles et al. (1987). In this study, the last 20-year period of HISWR was considered as a short-term record from which a long-term synthetic record could be generated. If a short-term record is not available for the location of interest, published parameter values are available (Richardson et al. 1987). These parameters, however, were developed from weather records of representative cities throughout the United States and may not be adequate for all locations because of elevation or other local conditions. When available, weather data from the location of interest are the best source of information.

To help determine the length of the weather record needed for developing parameters for CLIMGN, we examined the effect of record length on the annual mean values of precipitation, air temperature and solar radiation. These annual means are used by CLIMGN to determine the mean annual amounts of precipitation and mean annual temperatures of the generated weather record. Moving 10-, 20-, and 30-year means were calculated from HISWR. For example, 1914-1923 is one 10-year period; 1915-1924 is another; and so on. This procedure was used to identify all possible 10-, 20-, and 30-year periods in the 71-year HISWR.

\section{Model Simulation}

We used the Ekalaka Rangeland Hydrology and Yield Model (ERHYM) (Wight and Neff 1983) in this study. ERHYM is a climate, water-balance model that provides daily simulation of soil water evaporation, transpiration, soil water routing and runoff for individual range sites. Herbage yield is computed annually at peak standing crop as the product of the actual to potential transpiration ratio and the site yield potential. ERHYM calculates infiltration and runoff from daily rainfall using a modified curve number method as described by Williams and LaSeur (1976). Evapotranspiration, soil water routing, and herbage yield calculations are from Wight and Hanks (1981).

Forecasts of peak standing crop herbage yields and runoff based on initial soil water conditions were calculated using the HISWR, TSGEN, and ALLGEN weather records. Forecast values were determined by running the model for 71 years and calculating the means and standard deviations of the annual yield and runoff values (Wight et al. 1984). Five levels of initial soil water content were used in the model simulations: $0,25,50,75$, and $100 \%$ of the available soil water holding capacity. The model was run for only the duration of the growing season each year and soil water content was re-initialized annually. Runoff values represent only growing season runoff. The means of simulated yield and runoff using
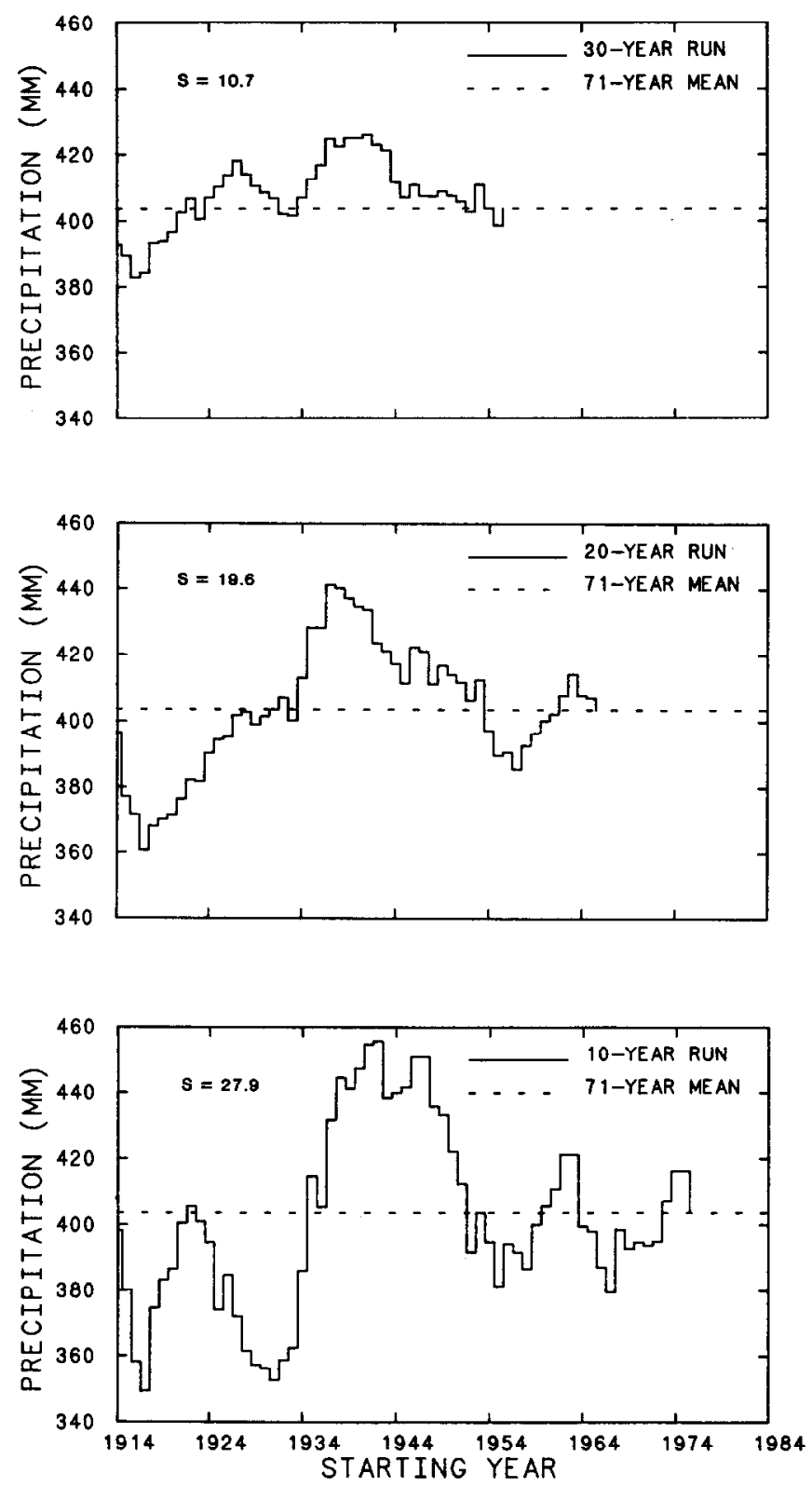

Fig. 1. Moving means and standard deviation (s) for annual precipitation for 10-, 20-, and 30-year periods of the HISWR.

HISWR, TSGEN, and ALLGEN were compared using a $t$-test.

\section{Results and Discussion}

The moving means plotted in Figures 1, 2, and 3 demonstrate the effect of record length on mean values of annual precipitation and daily maximum and minimum air temperatures. For precipitation, the means of the 10-, 20, and 30-year periods varied by 106,81, and $43 \mathrm{~mm}$, respectively. For example, in Figure 1 the lowest 10-year mean was $348 \mathrm{~mm}$ and the highest was $454 \mathrm{~mm}$, a difference of 106 $\mathrm{mm}$. Such variability does not mean that all generated records would be biased by such amounts. The probability of using a record with an extreme bias is low, but it could occur and bias decisions based on use of the synthetic weather record. Air temperatures were less variable with no differences among the 3 record periods greater than $1.5^{\circ} \mathrm{C}$. Based on the 31-year historical record, annual solar radiation means varied less than $1 \%$ for the 10 - and 20-year records.

As inputs to ERHYM or similar simulation models, the extreme biases in precipitation could significantly affect model output values, especially runoff. The small variation in temperature and 

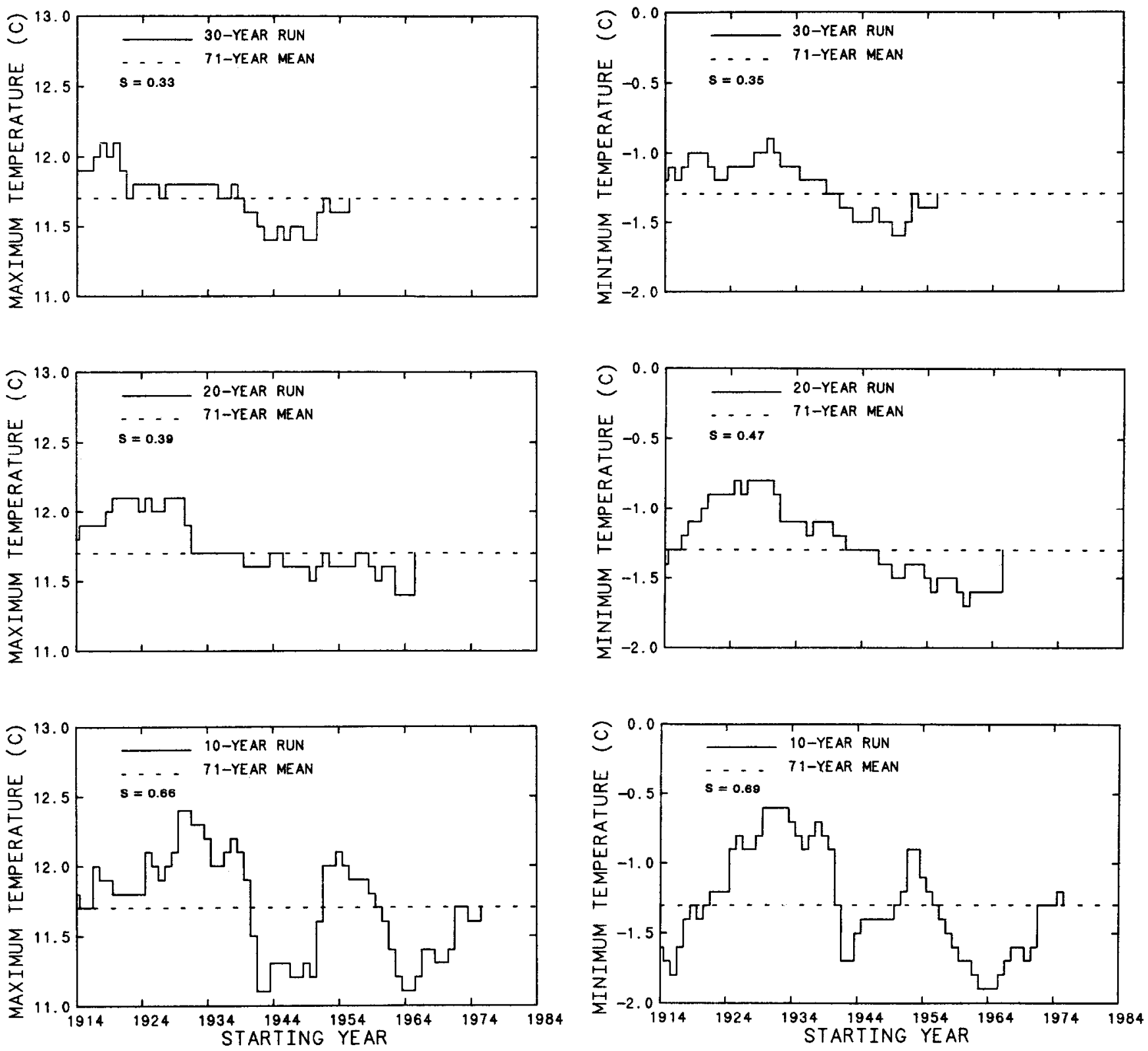

Fig. 2.Moving annual means of the daily maximum temperature values and the standard deviation (s) 10-, 20-, and 30-year periods of the HISWR.

solar radiation would have very little effect on herbage production or runoff. However, where temperature is a factor in determining competitive advantages among plant species in a multispecies model such as SPUR (Wight and Skiles 1987), small changes in temperature may be important.

The results of these 10-, 20-, and 30-year mean comparisons support the recommendations of Richardson et al. (1987). They recommend that for generating air temperature and solar radiation, a 10-year historical record is adequate for calculating model parameters. For precipitation, the historical record should be 20 years or more. Tables 1 and 2 compare attributes of the long-term weather records used in this study. Although there were some measurable differences in monthly precipitation means of the historical and synthetic records, these differences were generally small and did not affect the yield forecasts (Table 3). The largest discrepancy was in the September means, which were 37 and $52 \mathrm{~mm}$ for the historical and synthetic records, respectively. The major problem with the generated precipitation records was their inability to

Fig. 3. Moving annual means of the daily minimum temperature values and the standard deviation (s) for 10-, 20, and 30-year periods of the HISWR.

simulate daily extremes (Table 1). The historical record daily maximum precipitation values for each month were higher than the synthetic maximum values and for 5 of the 12 months, they were more than double the synthetic values. These extreme daily precipitation amounts are of major hydrologic importance.

Monthly means and extremes of the generated air temperature record were generally in good agreement with those of the historical records (Table 2). There were some measurable differences between the monthly means of the 2 records, but these differences are considered small (less than $1.9^{\circ} \mathrm{C}$ ). Annual means of the long-term records differed by only $0.1^{\circ} \mathrm{C}$.

Use of synthetic weather records had little effect on herbage yield forecasts determined from model simulations (Table 3). Forecasted values using HISWR and TSGEN were almost identical for both yield and runoff indicating that synthetic temperature values did not affect model simulations of yield or runoff.

Forecasted runoff, however, was affected by the use of synthetic precipitation records (ALLGEN). The forecasted annual runoff values were significantly lower $(P<.10)$ using the synthetic precipi- 
Table 1. Comparison of historical and synthetic precipitation records.

\begin{tabular}{lccccc}
\hline \hline & \multicolumn{4}{c}{ Precipitation (mm) } \\
Month & Mean & & Maximum daily values \\
\cline { 2 - 3 } \cline { 5 - 6 } \cline { 5 - 6 } January & 10 & 9 & & 17 & 11 \\
February & 10 & 8 & & 26 & 10 \\
March & 18 & 14 & & 46 & 18 \\
April & 38 & $50^{*}$ & & 50 & 59 \\
May & 54 & 45 & & 51 & 44 \\
June & 88 & 80 & & 101 & 50 \\
July & 59 & 61 & & 86 & 56 \\
August & 44 & 44 & & 74 & 47 \\
September & 37 & $52^{*}$ & & 127 & 49 \\
October & 24 & $32^{*}$ & & 49 & 45 \\
November & 13 & $9 *$ & 33 & 15 \\
December & 9 & 10 & & 19 & 13 \\
\hline Annual & 404 & 414 & Mean & 56 & 35 \\
\hline
\end{tabular}

*These means are significantly different $(P<.10)$ from the historical record means.

tation than they were using the historical precipitation record. Again, this difference in runoff reflects the inability of synthetic precipitation records to reflect the extreme daily precipitation values. Other workers have reported similar results when using synthetic precipitation records (Hanson et al. 1989, Zucchini and Adamson 1984).

\section{Conclusions}

Our results indicate that use of synthetic weather records can provide unbiased herbage yield forecasts using models such as ERHYM. Runoff, however, is very sensitive to extreme daily precipitation amounts which most synthetic records are unable to represent adequately. Climate model parameters for generating daily precipitation should be computed from no fewer than 20 years of historical records. For temperature and solar radiation, a 10-year historical record appears to be adequate. Synthetic weather records can be used effectively with rangeland simulation models in the decision-making process.

\section{Literature Cited}

Arkin, G.F., S.J. Mass, and C.W. Richardson. 1980. Forecasting grain sorghum yields using simulated weather data and updating techniques. Trans. ASAE 23:676-680.

Hanson, C.L., H.B. Osborn, and D.A. Woolhiser. 1989. Daily precipitation simulation model for mountainous areas. Trans. ASAE 32:865-873.

Larsen, G.A., and R.B. Pense. 1981. Stochastic simulation of daily climatic data. USDA-Statistical Reporting Service, Res. Div., Rep. AGES810831 .

Matalas, N.C. 1967. Mathematical assessment of synthetic hydrology. Water Resour. Res. 3:937-945.

Nicks, A.D., and J.F. Harp. 1980. Stochastic generation of temperature and solar radiation data. J. Hydrology 48:17-17.

Richardson, C.W. 1981. Stochastic simulation of daily precipitation, temperature, and solar radiation. Water Resour. Res. 17:182-190.
Table 2. Comparison of a historical (HISWR) and a synthetic (TSGEN) temperature record in terms of average monthly means and monthly extremes.

\begin{tabular}{lrrrrr}
\hline \hline & \multicolumn{4}{c}{ Temperature ${ }^{\circ} \mathrm{C}$} \\
\cline { 6 - 6 } \cline { 5 - 6 } Month & Mean & Range & & Mean & Range \\
\hline January & -13.2 & -42 to 17 & & $-11.3^{*}$ & -42 to 27 \\
February & -10.4 & -43 to 20 & & -9.6 & -41 to 24 \\
March & -3.6 & -34 to 28 & & -3.6 & -41 to 26 \\
April & 5.7 & -22 to 34 & & $4.1^{*}$ & -19 to 36 \\
May & 12.4 & -11 to 39 & & 12.6 & -10 to 39 \\
June & 17.7 & -2 to 41 & & $18.7^{*}$ & 1 to 41 \\
July & 21.6 & 2 to 46 & & 21.6 & 4 to 43 \\
August & 20.5 & 0 to 43 & & $19.7^{*}$ & -1 to 43 \\
September & 14.3 & -10 to 40 & & 13.9 & -9 to 41 \\
October & 7.3 & -26 to 36 & & $5.4^{*}$ & -22 to 34 \\
November & -1.7 & -30 to 26 & & $-2.7^{*}$ & -30 to 28 \\
December & -9.6 & -43 to 16 & & -8.6 & -37 to 26 \\
\hline Annual & 5.21 & -43 to 46 & & $5.1^{1}$ & -42 to 43 \\
\hline
\end{tabular}

*These means are statistically different $(P<.10)$ from the historical record means.

Annual means.

Richardson, C.W. 1985. Weather simulation for crop management models. Trans. ASAE 28:1602-1606.

Richardson, C.W., and D.A. Wright. 1984. WGEN: A model for generating daily weather variables. USDA-ARS, ARS-8.

Richardson, C.W., C.L. Hanson, and A.L. Huber. 1987. Climate generator, Ch. 2., Part I, Documentation, p. 3-16. In: Wight, J.R., and J.W. Skiles, eds., SPUR Simulation of Production and Utilization of Rangelands, Documentation and User Guide. USDA-ARS, ARS-63.

Rogler, G.A. 1951. A twenty-five year comparison of continuous and rotational grazing in the Northern Plains. J. Range Manage. 4:35-41.

Skiles, J.W., E.P. Springer, and C.W. Richardson. 1987. User guide for the climate generator, Ch. 4, Part II. User Guide, p. 235-239. In: Wight, J.R., and J.W. Skiles, eds., SPUR Simulation of Problems and Utilization of Rangelands, Documentation and User Guide. USDA-ARS. ARS-63.

Weaver, J.E., and F.E. Clements. 1938. Plant ecology. McGraw-Hill, New York.

Wight, J.R. 1987. Introduction to SPUR, Ch. I, Part I.-Documentation, p. 1-2. In: Wight, J.R., and J.W. Skiles, eds. SPUR Simulation of Production and Utilization of Rangelands, Documentation and User Guide. USDA-ARS, ARS-63.

Wight, J.R., and E.L. Neff. 1983. Soil-vegetation-hydrology studies, Vol. II. A users manual for ERHYM: The Ekalaka Rangeland Hydrology and Yield Model. USDA-ARS, Agr. Res. Results, ARS-W-29.

Wight, J.R., and J.W. Skiles, eds. 1987. SPUR: Simulation of Production and Utilization of Rangelands. Documentation and User Guide. USDAARS-3.

Wight, J.R., and R.J. Hanks. 1981. A water-balance, climate model for range forage production. J. Range Manage. 34:307-311.

Wight, J.R., C.L. Hanson, and D. Whitmer. 1984. Forecasting yearly herbage production using weather records. J. Range Manage. 37:3-6.

Williams, J.R., and W.V. LaSeur. 1976. Water yield model using SCS curve members. J. of the Hydraul. Div., ASCE, 102:1241-1253.

Zucchini, W., and P.T. Adamson. 1984. The occurrence and severity in droughts in South Africa. Dep. Civil Eng., Univ. Stellenbosch and Dep. Water Affairs, WRC Rep. 91/1/84.

Table 3. Herbage yield and runoff forecasts using historical (HISWR) and simulated weather records (TSGEN = air temperature and solar radiation generated; ALLGEN = precipitation, temperature, and solar radiation generated).

\begin{tabular}{|c|c|c|c|c|c|c|c|c|c|c|c|c|}
\hline \multirow{3}{*}{$\begin{array}{l}\text { Beginning }{ }^{1} \\
\text { soil water } \\
\text { content }(\%)\end{array}$} & \multicolumn{6}{|c|}{ Yield $(\%)^{2}$} & \multicolumn{6}{|c|}{ Runoff (mm) } \\
\hline & \multicolumn{2}{|c|}{ HISWR } & \multicolumn{2}{|c|}{ TSGEN } & \multicolumn{2}{|c|}{ ALLGEN } & \multicolumn{2}{|c|}{ HISWR } & \multicolumn{2}{|c|}{ TSGEN } & \multicolumn{2}{|c|}{ ALLGEN } \\
\hline & Mean & Std & Mean & Std & Mean & Std & Mean & Std & Mean & Std & Mean $^{3}$ & Std \\
\hline 0 & 42 & 24 & 42 & 24 & 38 & 23 & 9 & 14 & 9 & 13 & 2 & 5 \\
\hline 25 & 56 & 21 & 57 & 21 & 54 & 22 & 13 & 19 & 12 & 18 & 7 & 7 \\
\hline 50 & 71 & 16 & 71 & 16 & 70 & 18 & 20 & 25 & 19 & 24 & 9 & 11 \\
\hline 75 & 82 & 11 & 82 & 11 & 81 & 13 & 32 & 32 & 31 & 31 & 19 & 18 \\
\hline 100 & 88 & 8 & 88 & 8 & 87 & 10 & 50 & 38 & 49 & 36 & 37 & 24 \\
\hline
\end{tabular}

'Beginning soil water content is expressed as percent of the available soil water holding capacity.

${ }^{2}$ Yield is expressed as percent of the potential site yields with water nonlimiting for plant growth

${ }^{3}$ All the means in this column are significantly different $(P<.10)$ from the runoff means under HISWR and ALLGEN. 